\title{
Histopathological Evaluation of Surgically Treated Renal Lesions
}

\author{
Disha Singla ${ }^{1}$ and Gunvanti Rathod ${ }^{2 *}$ \\ ${ }^{1}$ Department of Pathology, Delhi Heart Hospital, Bathinda, Panjab, India \\ ${ }^{2}$ Department of Pathology, GMERS Medical College, Valsad, Gujarat, India
}

\begin{abstract}
Background: Nephrectomy is a common procedure in surgical practice. It is indicated in patients presenting with symptomatic chronic infections, obstruction, calculus disease, and severe traumatic injury to renal cell carcinomas.

Methods: The present study was conducted in the Department of Pathology and included all nephrectomy specimens received in the department over a period of five years (January 2011 - December 2015). Patient particulars were recorded, which included age, sex, chief complain and clinical findings; investigations such as CT scan, USG, and other relevant investigations were also noted. Meticulous histopathological examination was done and diagnosis was given.

Result: Total 124 patients underwent nephrectomy for various renal lesions in the last 5 years. There were 93 (75\%) male and 31 (25\%) female patients. In 12 patients, tumor was diagnosed on routine abdominal ultrasonographic screening for some other complains. Flank pain was the most common presenting symptom observed in $76(61.29 \%)$ patients, followed by hematuria in $22(17.54 \%)$ patients. On histopathological examination, $94(75.80 \%)$ were non-neoplastic renal lesions and $30(15.20 \%)$ were tumors. In non-neoplastic lesions of total nephrectomy specimens chronic pyelonephritis $70(56.46 \%)$ was the most common type of lesions followed by pyonephrosis 9 (7.26\%). There was also presence 4 (3.23\%) of cases of Tuberculosis kidney. Overall, RCC was the most common 20 (16.13\%) renal tumor.
\end{abstract}

Conclusion: The present study provides a fair insight into the histological patterns of lesions in nephrectomy specimens in our institution and its correlation with studies conducted across the world.

Keywords: Histopathology, Surgery, Renal Lesion, Evaluation.

\section{Introduction}

Nephrectomy is a common procedure in surgical practice. It is indicated in patients presenting with a wide range of clinical conditions ranging from symptomatic chronic infections, obstruction, calculus disease, and severe traumatic injury to renal cell carcinomas. Primary renal tumors comprise a wide spectrum of neoplastic lesions of the kidney with patterns, which are relatively distinct among children and adults. A wide variety of both benign and malignant renal tumors may arise from the different components of the renal parenchyma, mostly from the tubular epithelium. Acute histopathological diagnosis of all renal lesions is not possible before their surgical removal. A meticulous and detailed histopathologic examination of tumor nephrectomy specimens is essential for the accurate diagnosis, classification, prognostication and management of the renal lesions. ${ }^{[1-7]}$ In the present study, we aimed to analyze different histopathological varieties of renal lesions of the patients who underwent nephrectomy.

\section{Materials and Methods}

The present study was conducted in the Department of Pathology and included all nephrectomy specimens received in the department over a period of five years (January 2011 - December 2015). A total of 124 cases of nephrectomy specimen were studied during this period. Patient particulars were recorded, which included age, sex, chief complain and clinical findings; investigations such as CT scan, USG, and other relevant investigations were also noted. At the time of primary reporting, nephrectomy specimens were received fixed in $10 \%$ buffered formalin. Gross handling of nephrectomy specimens was done according to the standard protocol for examining nephrectomy specimens. ${ }^{[2,3,8,9]}$ Representative tissue blocks were taken and processed for paraffin embedding, hematoxylin and eosin ( $\mathrm{H}$ and $\mathrm{E}$ ) stained and examined by the pathologists. Special stains and immunohistochemistry were also done where needed. Meticulous histopathological examination was done and diagnosis was given. World Health Organization classification of renal tumors was followed for the histopathological diagnostic categorization of the tumors. ${ }^{[10]}$ Fuhrman, et al. nuclear grading system was done for grading the conventional clear cell and papillary variants of renal cell carcinoma (RCC). ${ }^{[1]}$ 


\section{Result}

A total of 124 patients underwent nephrectomy for their various renal lesions in the last 5 years. There were 93 (75\%) male patients and $31(25 \%)$ female patients; the male to female ratio was 3:1 (Table - 1).

In 12 patients, tumor was diagnosed on routine abdominal ultrasonographic screening for some other complains. Flank pain was the most common presenting symptom observed in $76(61.29 \%)$ patients, followed by hematuria in $22(17.54 \%)$ patients (Table - 2).

Analysis of the histopathological diagnosis of 124 nephrectomy specimens is given in (Table - 3). On histopathological examination, $94(75.80 \%)$ were non- neoplastic renal lesions and $30(15.20 \%)$ were tumors. In non-neoplastic lesions of total nephrectomy specimens, chronic pyelonephritis $70(56.46 \%)$ was the most common type of lesions followed by pyonephrosis 9 (7.26\%). Overall, RCC was the most common 20 (16.13\%) renal tumor. On the other hand, RCC was found to be the most common malignant renal tumor. Among the RCC, conventional, clear cell variety was found to be the most common histopathological variety followed by the papillary type, chromophobe type RCC (Figures - 1, 2, 3). There was also presence $4(3.23 \%)$ of cases of Tuberculosis kidney (Figure -4). There was also presence of one $(0.8 \%)$ case of well differentiated squamous cell carcinoma of renal pelvis (Figure - 5) and $2(1.60 \%)$ cases of angiomyolipoma.

Table 1: Gender-wise distribution of benign and malignant lesions.

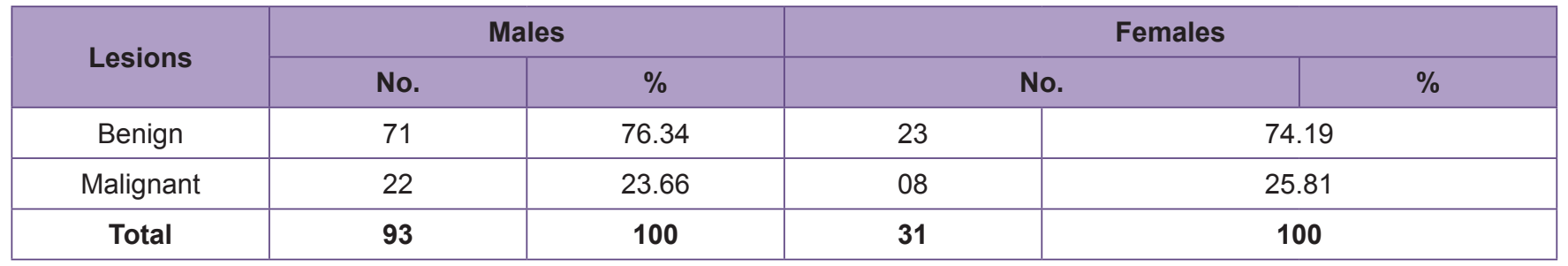

Table 2: Clinical presentation in patients undergoing nephrectomy.

\begin{tabular}{|c|c|c|}
\hline Clinical features & No. of patients & 61.29 \\
\hline Flank pain & 76 & 3.22 \\
\hline Fever & 04 & 5.64 \\
\hline Lump in abdomen & 07 & 9.67 \\
\hline Burning micturition & 12 & 17.54 \\
\hline Hematuria & 22 & 2.64 \\
\hline Vomiting & 03 & 100 \\
\hline Total & 124 & \\
\hline
\end{tabular}

Table 3: Distribution of nephrectomy specimens according to histopathological lesions.

\begin{tabular}{|c|c|c|}
\hline Lesion & No. of cases & \% \\
\hline Chronic pyelonephritis & 70 & 4.04 \\
\hline $\begin{array}{c}\text { Xanthogranulomatous } \\
\text { Pyelonephritis }\end{array}$ & 05 & 7.26 \\
\hline Pyonephrosis & 09 & 4.84 \\
\hline Traumatic kidney damage & 06 & 3.23 \\
\hline Tuberculosis kidney & 04 & 4.84 \\
\hline Wilms' tumor & 06 & 16.13 \\
\hline Renal cell carcinoma & 20 & 0.80 \\
\hline Squamous cell carcinoma & 01 & 1.60 \\
\hline Angiomyolipoma & 02 & 0.80 \\
\hline Renal sarcoma & 01 & \\
\hline
\end{tabular}




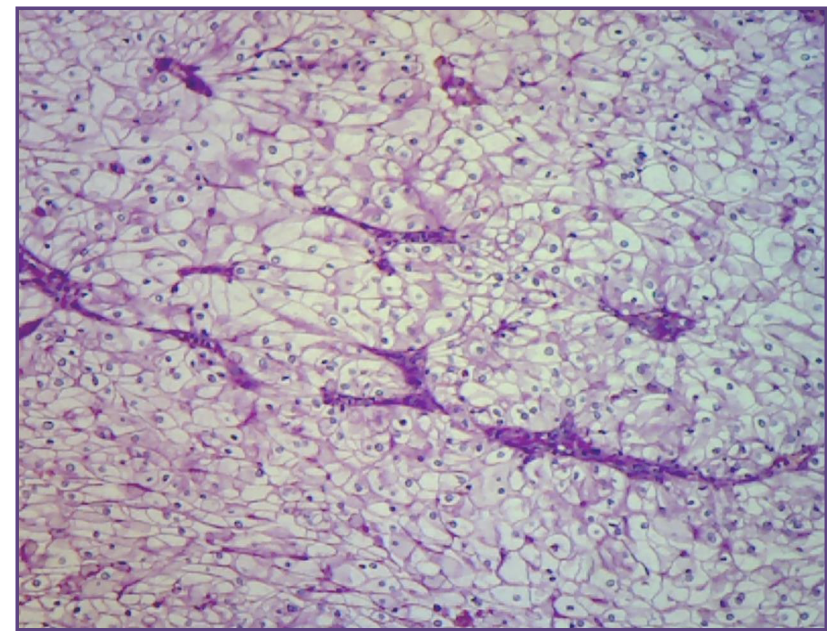

Fig. 1: Renal cell carcinoma of clear cell type (H \& E Stain, 10X).

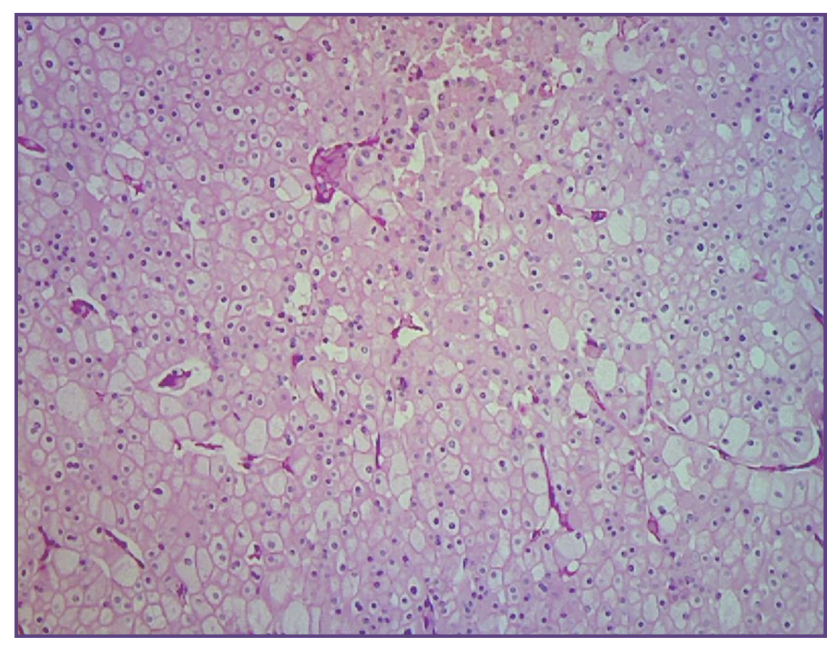

Fig. 3: Cells with abundant eosinophilic cytoplasm in chromophobe RCC (H \& E Stain, 10X).

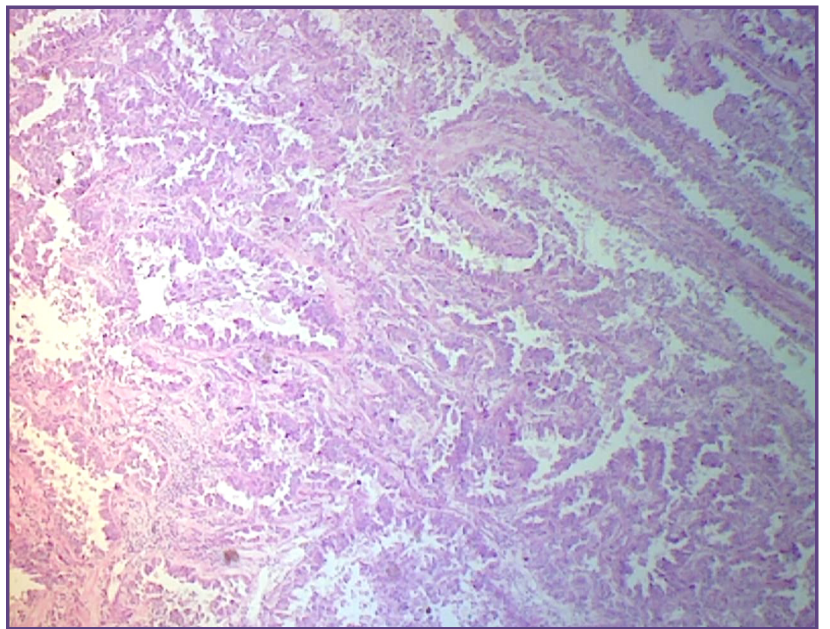

Fig. 2: Papillary type of renal cell carcinoma (H \& E Stain, 10X).

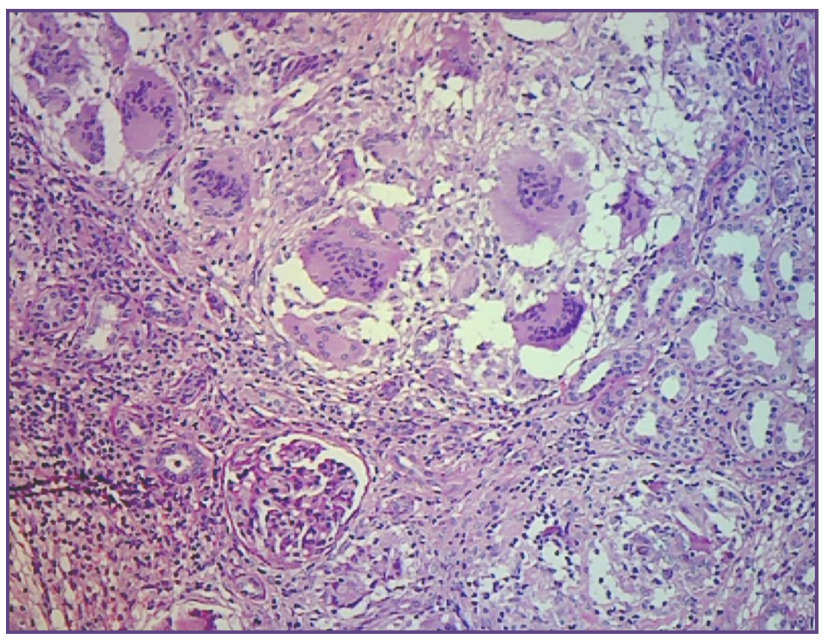

Fig. 4: Granuloma formation in Tuberculosis of kidney (H \& E Stain, 10X).

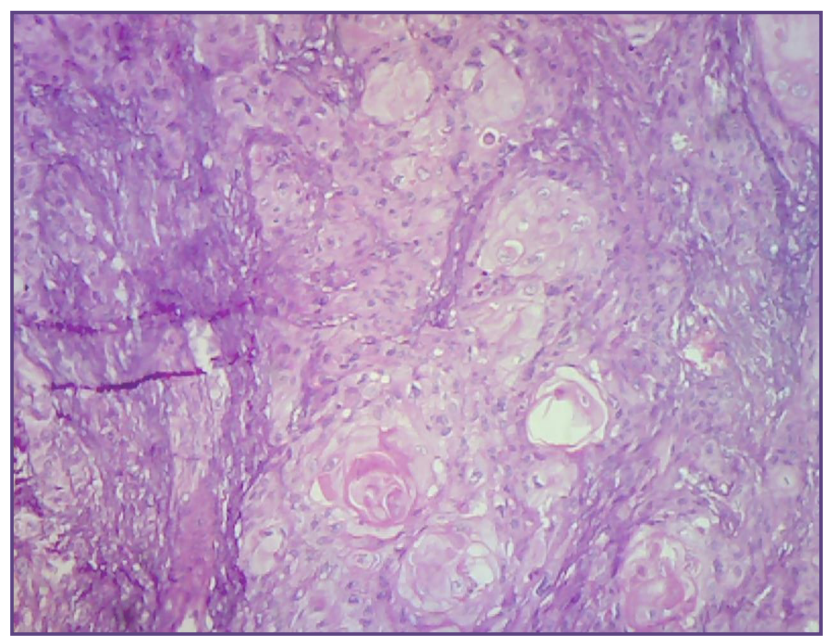

Fig. 5: Well differentiated Squamous cell carcinoma of renal pelvis (H \& E Stain, 10X). 


\section{Discussion}

In the present study, out of the 124 nephrectomy specimens studied, $75.80 \%$ had benign lesions and $15.20 \%$ had malignant lesions. Thus, benign lesions comprised the vast majority of the cases in our study. The similar findings were observed in the study by Mohammad Rafique in which $76.6 \%$ had benign lesions and $23.4 \%$ had malignant lesions. ${ }^{[12]}$ The ratio of M:F is 3:1 in our study which was in concordance with El Malik, et al. ${ }^{[13]}$ reported $61 \%$ nephrectomy specimens in males and 39\% in females with $\mathrm{M}: \mathrm{F}=1.9: 1$.

In the present study, the most common clinical feature that the patients presented with was flank pain $76(61.29 \%)$ patients. This was followed by hematuria $22(17.54 \%)$ patients and burning micturition. A majority of patients who presented with hematuria had malignant lesions. These observations were comparable to those in the study conducted by Popat, et al. ${ }^{[14]}$ and El Malik, et al. ${ }^{[13]}$

In the present study, the most common indication for nephrectomy was chronic pyelonephritis (56.46\%), followed by renal cell carcinoma (16.13\%). Chronic pyelonephritis has been reported as the most common clinical indication in the studies by Popal, et al., ${ }^{[14]} \mathrm{El}$ Malik, et al., ${ }^{[13]}$ and Ibrahim Ghalayeni. ${ }^{[15]}$ Nine cases of pyonephrosis were observed to comprise $7.26 \%$ of nephrectomy specimens.

In the present study, 8 (5.7\%) cases of xanthogranulomatous pyelonephritis were seen. Popat, et al. ${ }^{[14]}$ observed 2 cases (2.5\%), El Malik, et al., ${ }^{[13]} 6$ cases (1.1\%), and D'Costa, et al. ${ }^{[16]}$ found $10 \%$ cases of xanthogranulomatous pyelonephritis in 188 nephrectomy specimens. Among the cases of xanthogranulomatous pyelonephritis in the present study, 2 were male and 3 female. Thus, a female predilection was noted. A similar female predilection was observed by Parsons, et al ${ }^{[17]}$ and KB Koh. ${ }^{[18]}$

In the present study, a total of $30(23.4 \%)$ malignant lesions were observed; of these, a vast majority comprised renal cell carcinomas, i.e., $20(66.67 \%)$ cases. This was similar to the findings of Mohammad Rafique ${ }^{[12]}$ who observed that the majority of malignant neoplasms $(97 \%)$ of the kidney were renal cell carcinomas. Popat, et al., ${ }^{[14]}$ in their study, found that $70 \%$ of malignant lesions were accounted for by renal cell carcinomas. Among renal cell carcinomas, a majority of cases (72\%) were seen in males and $28 \%$ in females. Grossly, majority of tumors $(61 \%)$ involved the upper pole, followed by $37 \%$ tumors that involved the whole of the kidney. This was similar to the results by Popat, et al. ${ }^{[14]}$ who found majority of the tumors (57\%) involving the upper pole of the kidney.
In our study, microscopically, the clear cell type of renal cell carcinomas were the predominant type of tumor observed, involving 14 cases. This was followed by granular cell type in 3 cases and papillary type in 3 cases. Fuhrman nuclear grading ${ }^{[11]}$ revealed 10 cases showing Grade 2 nuclear features and 5 cases depicting Grade 3 nuclear features. Thus, majority of cases showed Grades 2 and 3 nuclear features. This is similar to the findings of Popat, et al., ${ }^{\left[{ }^{14]}\right.}$ who observed that all cases of conventional renal cell carcinomas showed Grades 2 and 3 nuclear features.

Two cases $(1.60 \%)$ of angiomyolipoma were seen in our study. Both the patients were female and presenting with pain and lump in the right lumbar region. No evidence of tuberous sclerosis was found in the patient. Popat, et al. ${ }^{[14]}$ reported two cases $(2.5 \%)$ of angiomyolipoma falling in the age group of 40-60 years. In our study, the patients with angiomyolipoma were having age of 45 and 56 years respectively. None of the patients showed features of tuberous sclerosis. El Malik, et al. ${ }^{[13]}$ reported 2 cases $(1.6 \%)$ of angiomyolipoma in a female patient with tuberous sclerosis. Thus a wide range of lesions were encountered when nephrectomy specimens are subjected to histopathological examination.

\section{Conclusion}

The present study provides a fair insight into the histological patterns of lesions in nephrectomy specimens in our institution and its correlation with studies conducted across the world. A wide range of lesions are encountered on histopathology of nephrectomy specimens, many of which may be misdiagnosed clinically and radiologically; therefore, it is mandatory that every nephrectomy specimen be subjected to a detailed histopathological examination for a clinico-morphological correlation to ensure proper management.

\section{Reference}

1. Algaba F, Trias I, Scarpelli M, Boccon-Gibod L, Kirkali Z, Poppel HV. Handling and pathology reporting of renal tumor specimens. Eur Urol., 2004; 45: 437-43.

2. Fleming S, Griffiths DFR. Best practice No 180. Nephrectomy for renal tumour: dissection guide and dataset. J Clin Pathol., 2005; 58: 7-14.

3. Rosai J. Guidelines for handling of most common and important surgical specimens. In: Rosai J, ed. Rosai and Ackerman's Surgical Pathology. 9th edition, St Louis: Mosby, 2004; p. 2911-77.

4. Furge KA, Lucas KA, Takahashi M, Sugimura J, Kort EJ, Kanayama H, et al. Robust classification of renal cell carcinoma based on gene expression data and predicated cytogenetic profiles. Cancer Res., 2004; 64: 4117-21. 
5. Srigley JR, Hutter RVP, Gelb AB, Henson DE, Kenney $\mathrm{G}$, King BF, et al. Current prognostic factors- renal cell carcinoma. Cancer, 1999; 80: 994-6.

6. Leibovich BC, Pantuck AJ, Bui MH, Ryu-Han K, Zisman A, Figlin R, et al. Current staging of renal cell carcinoma. Urol Clin North Am., 2003; 30: 481-97.

7. Moch H, Gasser T, Amin MB, Torhorst J, Sauter G, Mihatsch MJ. Prognostic utility of the recently recommended histologic classification and revised TNM staging system of renal cell carcinoma: a Swiss experience with 588 tumours. Cancer, 2000; 89: 604-14.

8. Amanullah, Saleem MA, Khan I, Qadri MW, Khan FA. Incidental Detection of Renal Cell Carcinoma. Ann King Edward Med Uni., 1999; 5: 196-8.

9. Siyal AR, Balouch QD, Shaikh SM, Surahio AW. Renal cell carcinoma. J Surg Pak., 2000; 5: 36-8.

10. Eble JN, Sauter G, Epstein JI, Sesterhenn IA, eds. Pathology and genetics of tumours of the urinary system and male genital organs. Lyon, France: IARC Press; 2004.

11. Fuhrman SA, Lasky LC, Limas C. Prognostic significance of morphologic parameters in renal cell carcinoma. Am J Surg Pathol., 1982; 6: 655-63.
12. Rafique M. Nephrectomy: Indications, complications and mortality in 154 consecutive patients. J Pak Med Assoc., 2007; 57: 308-11.

13. El Malik EM, Memon SR, Ibrahim AL, Al Gizawi A, Ghali AM. Nephrectomy in Adults: Asir Hospital Experience. Saudi J Kidney Dis Transpl., 1997; 8: 423-7.

14. Popat VC, Kumar MP, Udani D, Mundra MP, Vora DN, Porecha MM. A study on culprit factors ultimately demanding nephrectomy. Internet J Urol., 2010; 7.

15. Ghalayini IF. Pathological spectrum of nephrectomies in a general hospital. Asian J Surg., 2002; 25: 163-9.

16. D'Costa GF, Nagle SB, Wagholikar UL, Nathani RR. Xanthogranulomatous pyelonephritis in children and adults An 8 year study. Indian J Pathol Microbiol., 1990; 33: 224-9.

17. Parsons MA, Harris SC, Longstaff AJ, Grainger RG. Xanthogranulomatous pyelonephritis: A pathological, clinical and aetiological analysis of 87 cases. Diagn Histopathol., 1983; 6: 203-19.

18. Koh KB. Xanthogranulomatous Pyelonephritis in a Malaysian population. Singapore Med J., 1993; 34: 341-2.

*Corresponding author:

Dr. Gunvanti Rathod, Associate Professor, Department of Pathology, GMERS Medical College, Valsad, Gujarat, India

Phone: +91 8141905206

Email: neepath@gmail.com

Financial or other Competing Interests: None. 